\title{
NÍVEL TECNOLÓGICO E EMISSÃO DE POLUENTES: UMA ANÁLISE EMPÍRICA A PARTIR DA CURVA DE KUZNETS AMBIENTAL
}

\author{
Leonardo Andrade Rocha * \\ Ahmad Saeed Khan ${ }^{\dagger}$ \\ Patricia Verônica P. S. Lima
}

\begin{abstract}
Resumo
Esta investigação evidenciou a existência da curva U-invertida, Curva de Kuznets Ambiental, relacionando emissão de poluentes e nível tecnológico dos países. O modelo baseou-se na estimação de métodos de regressão com dados em painel, em amostra de 102 países durante 1960-2000. Adotando uma abordagem alternativa, o PIB per capita foi substituído pela Produtividade Total dos Fatores. Nos estágios iniciais do desenvolvimento, a adoção de tecnologias mais sujas pelas economias atrasadas torna-se essencial na geração do aprendizado e na trajetória futura de inovação. O impacto da regulação ambiental para estas economias pode agravar o gap tecnológico com a vizinhança da fronteira, nações desenvolvidas.
\end{abstract}

Palavras-chave: Curva Kuznets Ambiental; Poluição; Desenvolvimento Econômico.

\begin{abstract}
This investigation revealed the existence of a U-inverted curve, i.e. Environmental Kuznets Curve, relating pollutant emissions and technological level of the countries. The model was based on the estimation of regression methods with panel data, using 102 countries during 1960-2000. An alternative approach replaced GDP per capita, by the total factor productivity. In early stages of development, the adoption of dirtier technologies by backward economies is essential for generating knowledge and the future path of innovation. The impact of environmental regulation for these economies can aggravate the technological gap with its neighbors, the developed nations.
\end{abstract}

Keywords: Environmental Kuznets Curve; Pollution; Economic Development.

JEL classification: O40, Q50

\footnotetext{
${ }^{*}$ Universidade Federal Rural do Semi-Árido (PPGATS/UFERSA). E-mail: leonardoandrocha@yahoo.com.br

† Universidade Federal do Ceará (UFC). E-mail: saeed@ufc.br

‡ Universidade Federal do Ceará (UFC). E-mail: pvpslima@gmail.com
} 


\section{Introdução}

Os modelos tradicionais do crescimento expõem a importância da acumulação do capital e a geração do capital humano como os principais guiadores do desenvolvimento e de um padrão de vida similar àquele que as economias mais desenvolvidas atualmente desfrutam.

A crescente pressão de entidades não governamentais, formuladores de política e pesquisadores tem apresentado a limitação desses modelos, que menosprezam a utilização abundante dos recursos naturais, sem levar em consideração suas conseqüências, o que tem gerado um amplo debate sobre o cenário futuro da sociedade no Planeta. Economistas tradicionais e ecológicos concordam que o capital natural vem se tornado um fator crucial no processo de crescimento das nações, uma vez que atua como provedor de bens e serviços necessários à satisfação das necessidades de todos os seres vivos.

Em uma pioneira investigação, Grossman \& Krueger (1991) apresentaram a relação entre o crescimento econômico e os recursos naturais através de uma curva em formato de U-invertida, a então chamada "Curva de Kuznets Ambiental" ou CKA. Na verdade, o estudo dos autores mostrou as conseqüências da redução das barreiras comerciais sobre a degradação ambiental, de forma que os impactos da regulação do NAFTA para os EUA e Canadá consistiriam em uma maior especialização de atividades intensivas em capital humano e físico e na geração de "tecnologias limpas".

Em resumo, o beneficio líquido em nível global resultaria em uma intensa circulação das atividades econômicas "mais sujas" para ambientes de produção altamente regulamentados. Tal comportamento implicaria numa curva em formato de U-invertido, de forma que nos primeiros estágios do crescimento, a degradação e a poluição, seriam acontecimentos inevitáveis e essenciais para a condução a estágios posteriores em que altos níveis de renda conduziriam à melhoria do meio ambiente.

Visivelmente, muitos poluentes por unidade de produção em processos específicos têm diminuído seus níveis nos países desenvolvidos ao longo do tempo, em detrimento de rigorosas normas ambientais e por inovações tecnológicas que têm redirecionado o percurso para processos de produção cada vez mais limpos. Entretanto, a mistura de efluentes vem mudando gradativamente de forma que os resíduos sólidos ainda são elevados. Em níveis per capita, a emissão de resíduos não vem apresentando padrões de redução, pelo contrário, vem aumentando significativamente.

A atividade econômica é caracterizada pela existência de descontinuidades em pelo menos alguma parte do processo produtivo. Satisfazer as necessidades materiais e econômicas das pessoas que interagem no ambiente econômico exige, para além do uso, a perturbação dos fluxos de energia e no uso de materiais. Conseqüentemente, o esforço na redução de determinados impactos ambientais, em última instância, pode gerar uma transferência de problemas (Stern 2003, Suri \& Chapman 1998).

Na verdade, a hipótese do modelo CKA tem dividido o grupo de pesquisadores entre os que acreditam na relação das variáveis (Selden \& Song 1994, Stern \& Common 2001) e os que duvidam da sua existência (Arrow et al. 1995, Ekins 1997, Pearson 1994). Os argumentos de quem defende a CKA também são refutados por autores como De Bruyn et al. (1998), Torras \& Boyce (1998), Cole (2004). 
Segundo Stern et al. (1996), uma das limitações do modelo é o fato de que se os países pobres aplicassem os mesmos níveis de regulamentação ambiental das nações desenvolvidas, eles teriam que enfrentar a difícil tarefa de diminuir as atividades intensas em poluição - que nos estágios iniciais do aprendizado, tornam-se cruciais para a transição tecnológica - em vez da terceirização para outros países, o que comumente ocorre das economias desenvolvidas para as atrasadas (Stern 2003). Esse impacto da regulamentação ambiental de as "atividades poluentes" dos países desenvolvidos gravitarem para ps países em desenvolvimento encontra-se documentado em Lucas et al. (1992).

Considerando, ainda, que o uso de variáveis como o PIB per capita nos modelos CKA, muitas vezes falha em capturar o real papel da tecnologia na busca por padrões de crescimento ambientalmente sustentáveis, esta investigação propõe agregar elementos à validação da CKA na forma de U-invertido, ao analisar os impactos da Produtividade Total dos Fatores (PTF) na emissão de poluentes e conseqüentemente na degradação ambiental.

Estudos recentes sobre crescimento endógeno associam os diferentes níveis de tecnologia aos aspectos da degradação ambiental, de forma que as economias com maior atraso são mais intensivas no uso de tecnologias que degradam mais o ambiente em relação às economias mais avançadas ou da fronteira. Dessa forma, o efeito-composição de uso intensivo de insumos e tecnologias "sujas" que degradam mais o meio ambiente são mais bem observados nas economias mais afastadas da fronteira. Nesse contexto, os níveis de aprendizado que oferecem mais "chances" de permuta para as tecnologias mais "limpas" são mais difíceis de serem alcançados por tais economias.

Acemoglu et al. (2009) construíram um modelo nessa perspectiva distinguindo um modelo teórico que incorporava a produção final da economia usando setores intensivos em produção "suja" e "limpa". O gap observado entre os setores influencia na transição das tecnologias mais "sujas" para as mais "limpas", repercutindo (restringindo) diretamente nas taxas de crescimento de longo prazo. As tecnologias mais sujas são mais intensivas em recursos esgotáveis e por esta razão, as economias da fronteira utilizam menos tais recursos, dado que os setores são mais concentrados em tecnologias que demandam cada vez menos insumos. Além disso, a forte dinâmica tecnológica das "economias da fronteira" encontra-se mais propensa a oferece restrições ainda mais fortes para as economias em atraso.

Essa dinâmica pode oferecer uma "destruição de trajetórias tecnológicas" às economias menos providas de adaptação (Rocha et al. 2009). A "faceta do desenvolvimento" consiste não apenas da simples análise nas diferenças de renda observadas entre os países, mas também corresponde à verdadeira compreensão das relações de poder cujas economias com alto grau de domínio em tecnologias de ponta impõem restrições aos seguidores em decorrência da sua dinâmica tecnológica (Amsden 2001).

Este artigo encontra-se estruturado em sete seções. Na sequência desta introdução apresenta-se a seção 2 com o arcabouço teórico que ampara a necessidade de novas abordagens no tratamento do modelo CKA. Em seguida, na seção 3, encontra-se o estudo econométrico apropriado ao tratamento do modelo. A calibração para o cálculo da PTF é discutida na seção 4 e a fonte dos dados utilizados no estudo na seção 5. Por fim, as seções 6 e 7 trazem, respectivamente, a análise dos resultados e as considerações finais. 


\section{Abordagem de Kuznets ao meio ambiente}

A teoria da Curva de Kuznets Ambiental (CKA) ${ }^{1}$ foi primeiramente apresentada por Grossman \& Krueger $(1991,1995)$ que diagnosticaram os efeitos da redução das barreiras comerciais sobre o meio ambiente, por meio da alteração na escala (expansão) e na composição da atividade econômica e na mudança das técnicas de produção.

O estudo de Grossman \& Krueger (1995) baseou-se em um modelo crosssection para 42 países, relacionando a qualidade do ar com os níveis de crescimento econômico. Os autores concluíram que a concentração de poluentes aumenta com o PIB per capita em estágios iniciais com níveis de baixa renda e reduz com níveis mais altos, salientando um formato de U-invertido entre emissão de poluentes e os níveis de riqueza dos países. ${ }^{2}$ Tal comportamento pode ser explicado resumidamente da seguinte maneira: (a) nos estágios iniciais do processo de industrialização, o custo relativo entre renda e o meio ambiente, e a própria qualidade do ambiente regulatório são baixos. Consequentemente a sociedade acaba por optar pelo aumento dos níveis de emprego e renda mesmo que essa opção gere um acréscimo dos níveis de poluição; (b) nos estágios finais em que os setores industriais vão se tornando mais desenvolvidos e dinâmicos à mudança tecnológica, a própria sociedade opta ou pressiona por tecnologias mais "limpas" e dessa forma as instituições regulatórias vão se tornando mais efetivas quanto à execução de políticas de proteção ambiental. ${ }^{3}$

Costantini \& Martini (2007) afirmaram que o papel das instituições como variável endógena permite a compreensão necessária sobre quais fatores afetam indiretamente o desenvolvimento sustentável. As diferenças observadas nos níveis de PIB per capita, saúde e educação, são fundamentais para explicar a qualidade das políticas destinadas à proteção ambiental que variam entre os países desenvolvidos e em desenvolvimento. Dessa forma, as distintas características que definem e moldam o conjunto institucional entre os países repercutem diretamente na própria eficácia do instrumental político que pode tomar direções opostas entre nações desenvolvidas e em desenvolvimento.

De acordo com Deacon \& Norman (2006), a relação U-invertido entre poluição e renda corresponde a uma interpretação bastante ampla de como a qualidade ambiental se altera conforme o país passe por uma transição das condições de pobreza para uma nação desenvolvida. Nas democracias mais desenvolvidas, o controle das emissões de poluentes é mais rígido comparativamente aos países de rendas baixa e média. Portanto, as previsões do modelo da Curva de Kuznets Ambiental se adéquam ao padrão observado da degradação ambiental que aumenta monotonicamente para os baixos níveis de renda até um ponto de transição, quando a estrutura institucional força a mudança tecnológica necessária para reduzir os efeitos colaterais do rápido crescimento econômico.

\footnotetext{
${ }^{1}$ Em inglês Environmental Kuznets Curve (EKC).

${ }^{2}$ De acordo com os autores, a integração comercial entre os países pode gerar um aumento no fluxo de bens importáveis com uso intensivo de capital físico e humano, sobretudo para os países de baixa renda, o que pode contribuir para um rápido crescimento. A consequência desse padrão de crescimento pode ser observada no aumento gradativo de pressões políticas futuras no conjunto regulatório de proteção ambiental e na mudança dos padrões comportamentais do consumo privado.

${ }^{3}$ Para maiores detalhes ver Dasgupta et al. (2002).
} 
Conforme Dasgupta et al. (2002), a existência teórica de um ceticismo quanto à queda dos níveis de poluição a partir de um alto padrão tecnológico, "põe em cheque" a abordagem CKA, enfatizando que os altos níveis de renda observados nos países ricos não necessariamente reduziriam as emissões de poluentes. Entretanto, promoveria uma "corrida para a estabilidade" aos padrões ambientais. Desta forma a curva U-invertido deixaria de existir e uma assíntota seria observada a partir de um nível máximo de degradação ambiental quando as pressões políticas começam a limitar a trajetória de crescimento.

A Figura 1 apresenta uma linha horizontal no ponto máximo da emissão de poluentes. No contexto, a própria globalização promove uma relativa estabilidade na degradação ambiental e as economias continuam a crescer emitindo um nível "adequado" de poluição.

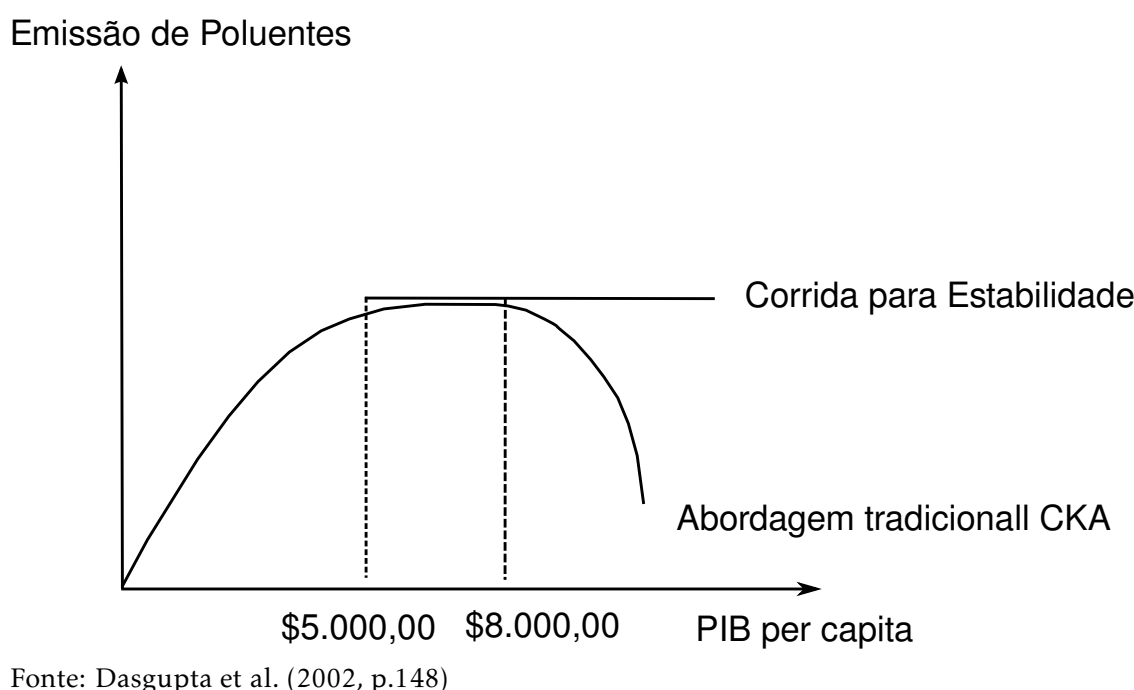

Fonte: Dasgupta et al. (2002, p.148)

Figura 1: Curva de Kuznets Ambiental

Ainda sobre o tema, Shafik \& Bandyopadhyay (1992) analisaram a relação entre renda e qualidade ambiental por meio de um estudo empírico entre uma amostra de países e concluíram que os níveis de concentração de dióxido de enxofre e de outros poluentes tendm a cair quando os níveis de renda de $\$ 3.000,00$ - $\$ 4.000,00$ começam a ser alcançados. Os autores utilizaram vários indicadores de deterioração ambiental e verificaram que a maioria, com exceção dos índices de acesso à água potável e saneamento urbano, tende a crescer rapidamente nos níveis iniciais de renda e posteriormente estabilizam-se chegando a reduzir com os altos padrões de renda. Os dados evidenciaram que diversas economias com elevadas taxas de investimento e um rápido crescimento econômico exercem fortes pressões sobre os recursos naturais, particularmente em termos de poluição.

A Figura 2 apresenta o padrão de cumulatividade das emissões de $\mathrm{CO}_{2}$, em nível de país, entre 1950-1999. As áreas com as maiores emissões cumulativas são predominantemente encontradas nas nações ricas do hemisfério norte, basicamente os Estados Unidos (com 27\% das emissões totais) e Europa (com $18 \%$ das emissões totais). Isso destaca que as economias mais desenvolvidas e situadas na fronteira tecnológica foram as que mais contribuíram para 
a degradação ambiental (Rocha et al. 2009).

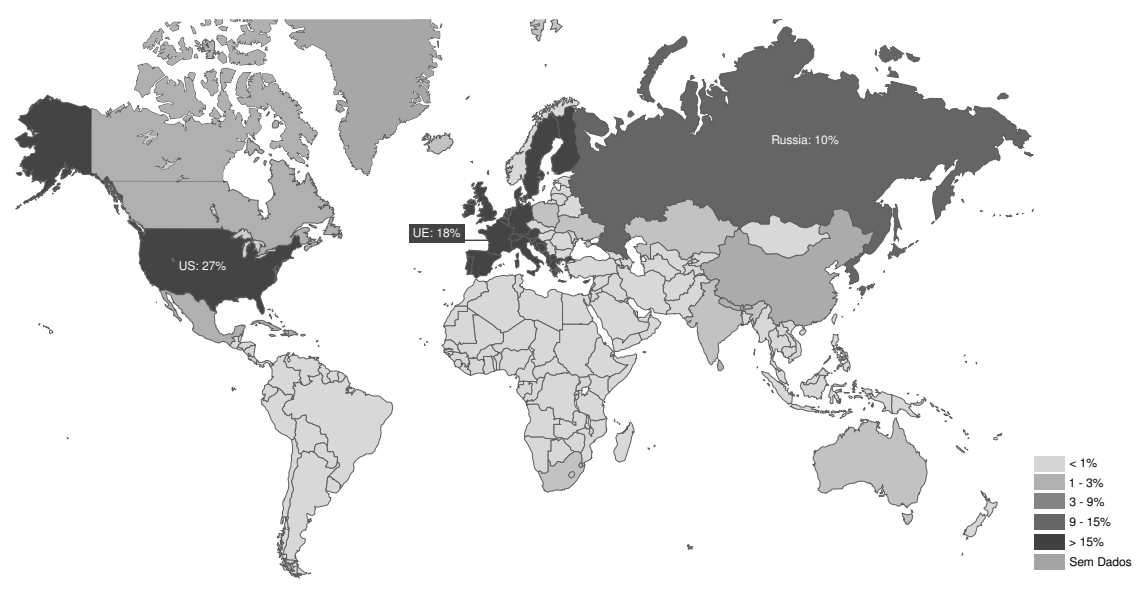

Fonte: Earth Trends (2001) World Resources Institute.

Figura 2: Emissões cumulativas de $\mathrm{CO}_{2}$ entre 1950 e 1999.

Algumas explicações sobre o formato U-invertido entre poluição e renda sugerem que os países desenvolvidos podem se beneficiar de significativas reduções nas concentrações de poluição por meio das relações comerciais com os países pobres e em desenvolvimento. Dessa forma, os países da OECD Organização para Cooperação e Desenvolvimento Econômico - têm maiores possibilidades de redução de poluentes como $\mathrm{CO}_{2}$ e $\mathrm{SO}_{2}$ por meio da terceirização de tecnologias mais "sujas" com o resto do mundo devido ao processo de especialização comercial (Stern et al. 1998).

Segundo He (2007), o próprio formato U-invertido corresponde a uma consequência dos padrões liberais da comercialização, ou seja, diversas indústrias passaram a ser redistribuídas entre as nações integradas o que permitiu um "efeito concentrador" para as economias mais pobres e um "efeito dissipador" para as economias ricas.

Entretanto, os atuais protocolos ambientais impossibilitam de forma mais atuante um crescimento sustentável aos países em desenvolvimento por restringir os pontos críticos de emissão, ${ }^{4}$ que juntamente com a dinâmica tecnológica da fronteira (países desenvolvidos), destroem a lá Schumpeter suas próprias trajetórias de crescimento. ${ }^{5}$

De acordo com Suri \& Chapman (1998), os modelos liberais de comercialização têm contribuído intensamente para a afirmação da curva U-invertida. Segundo os autores o movimento de mercadorias transacionadas entre os países desenvolvidos e em desenvolvimento, incorpora uma contribuição significativa para a poluição que não está sendo levada em consideração. Analisando

\footnotetext{
4Estes "pontos" correspondem ao ápice da curva U-invertido, denotando o nível de renda que maximiza a emissão de poluentes.

${ }^{5}$ Para maiores detalhes ver He (2007) e Rocha et al. (2009).
} 
o consumo de energia e o volume de bens comercializados entre os países, os autores verificaram que tanto as economias industrializadas quanto aquelas em industrialização têm acrescentado suas demandas por energia por meio da exportação de bens manufaturados, sendo que as economias em desenvolvimento têm contribuído para um crescimento maior de poluição do que as nações desenvolvidas. Consequentemente, os níveis de exportação dos países industrializados têm colaborado para a ascendência da curva U-invertido, enquanto que a importação tem ocasionado a queda observada na curva.

\section{Modelagem Ecnométrica}

A seguir serão vistos os principais estudos empíricos que quantificaram a relação U-invertido entre emissão de poluentes e renda dos países. Será primeiramente abordada a forma tradicional dos atuais modelos econométricos que utilizam métodos de estimação com dados em painel, relacionando a emissão de $\mathrm{CO}_{2}$ per capita como uma função polinomial do segundo grau do PIB per capita. Em seguida será apresentado um modelo alternativo associando a degradação ambiental com a produtividade total dos fatores.

\subsection{Framework Tradicional}

Diversos estudos evidenciaram a relação entre poluição e renda per capita como uma curva no formato U-invertido. ${ }^{6}$ Recentemente Stern (2009) evidenciou que os modelos de regressão em dados em painel têm ganhado grande notoriedade nos estudos que tentam evidenciar a Curva de Kuznets Ambiental. O uso de modelos com dados em painel tem gerado estimativas mais consistentes dos "pontos críticos de emissão" e das elasticidades por incluir diferenças no tempo e entre os países.

De acordo com Stern $(2003,2009)$, o modelo CKA tradicional utilizado para dados em painel tem sido usualmente estimado da seguinte maneira:

$$
\ln \left(\frac{E_{i t}}{P_{i t}}\right)=\alpha+\beta_{1} \ln \left(\frac{P I B_{i t}}{P_{i t}}\right)+\beta_{2}\left(\ln \left(\frac{P I B_{i t}}{P_{i t}}\right)\right)^{2}+\mu_{i}+\gamma_{t}+\varepsilon_{i t}
$$

sendo $E_{i t}, P_{i t}, P I B_{i t}$ correspondentes, respectivamente, às emissões de $\mathrm{CO}_{2}$, à população e ao PIB do país " $i$ " no tempo " $t$ ". Segundo Stern et al. (1998) os modelos para dados em painel, com ênfase nos modelos fixos e aleatórios, mostraram que, o primeiro método de estimação revelou-se mais consistente para os estudos da CKA devido a fortes indícios empíricos de uma correlação entre as variáveis explanatórias e os vetores de controle. ${ }^{7}$

Baseado na equação (1), o "ponto crítico" da Curva de Kuznets Ambiental pode ser estimado por meio da seguinte expressão: ${ }^{8}$

$$
\tau=e^{\left(\frac{-\beta_{1}}{2 \beta_{2}}\right)}
$$

\footnotetext{
${ }^{6}$ Veja Stern \& Cleveland (2004), Perman \& Stern. (2001), Stern (2003, 2009), Andreoni \& Levinson (2001), Bruvoll \& Medin (2003), Bulte \& Van Soest (2001), Harbaugh et al. (2002), Wagner (2008) dentre outros pesquisadores.

${ }^{7}$ Esta identificação pode ser obtida pelo teste de Hausman. Ver Hausman (1978), Hsiao (2003) Baltagi (2008).

${ }^{8}$ Veja Stern (2003).
} 
O estudo de Stern et al. (1998) apresentou estimativas do "ponto crítico" da ordem de $\$ 9.201,00$ de PIB per capita. O modelo estimado baseou-se numa amostra de 23 países da OECD e, dessa forma, em níveis de renda acima disso, sendo que os níveis de emissões de poluição no ar apresentaram quedas significativas na amostra.

Stern (2009) encontrou uma enorme variabilidade de medidas de "pontos críticos" baseadas em estimativas do modelo (1), conforme diferentes métodos de estimação. ${ }^{9} \mathrm{O}$ autor utilizou as mesmas amostras de países usadas por Vollebergh et al. (2009) e por Stern \& Common (2001), com emissões de enxofre e $\mathrm{CO}_{2}$ como índices de degradação. De acordo com o autor, as medidas para mensurar os "pontos críticos" de emissão são bastante discrepantes, porém a relação U-invertido entre degradação ambiental e renda ainda se mostra significativa.

Uma das críticas ao modelo representado na equação (1) reside na omissão de variáveis. Segundo Stern (2003), a vantagem do teste de Hausman em modelos em painel consiste em evidenciar a possível existência de fatores não observados correlacionados com os regressores. Na existência de uma possível heterogeneidade não observada, a utilização de modelos de efeitos fixos controlados por diferenças entre países e no tempo permite uma estimação mais consistente dos parâmetros, porém sem o uso da construção de séries de previsão. A seguir será apresentado o modelo proposto nesta investigação.

\subsection{Modelo Empírico Alternativo}

A literatura tradicional tenta quantificar a relação entre degradação ambiental e renda relacionando as emissões de poluentes per capita e o PIB per capita. Entretanto, nenhum estudo buscou analisar empiricamente a relação entre as emissões de poluentes e o nível tecnológico entre os países (Produtividade Total dos Fatores - PTF). Ao contrário da renda per capita como indicador de inflexão, a PTF mostra a transição da tecnologia entre padrões com alta degradação ambiental (geralmente proveniente da difusão de tecnologias sujas da fronteira para os seguidores) para tecnologias poupadoras de degradação, ${ }^{10}$ à medida que o gap tecnológico vai se reduzindo no tempo (aproximação com a fronteira tecnológica).

$\mathrm{Na}$ abordagem da Produtividade Total dos Fatores, três fatores principais sustentam as evidências da relação entre as emissões de poluentes e o nível tecnológico entre os países: o fator escala da produção, o fator composição da produção e o fator tecnológico. No primeiro caso, os estágios iniciais do desenvolvimento são marcados pela transição das economias agrícolas para os parques industriais, e, portanto, a utilização de tecnologias com elevado grau de degradação é inevitável para os países que avançam com suas políticas industriais. Nessa fase, os países de renda baixa e média são caracterizados por uma grande influência do "efeito-escala", destacando que nesse segundo grupo de países, o efeito composição tende a "suavizar" os efeitos da degradação (Stern et al. 1998). No tocante às economias desenvolvidas, o grande "peso" do fator tecnológico vinculado à composição da produção, faz com que as emissões venham a apresentar uma queda ao longo do tempo, fazendo com que a re-

\footnotetext{
${ }^{9} \mathrm{O}$ autor estimou o modelo com dados em painel segundo os métodos: efeitos fixos, efeitos aleatórios, e modelo de primeiras diferenças.

${ }^{10}$ Esta proposição está documentada no trabalho dos autores Acemoglu et al. (2012).
} 
lação Desenvolvimento versus Degradação apresente-se por meio de uma curva U-invertido.

Contudo, sabe-se por meio de uma ampla literatura, ${ }^{11}$ que os estágios de desenvolvimento $^{12}$ estão muito mais ligados à trajetória de aprendizado e à criação de novas tecnologias do que à simples menção com a renda da economia. Muitos países em atraso possuem grandes restrições no manuseio e desenvolvimento das tecnologias avançadas da fronteira (Caselli \& Coleman 2006). A este grupo de países, as restrições de aprendizado conferem grandes barreiras aos padrões de domínio da tecnologia (Malerba \& Orsenigo 1997). Este "paradigma do desenvolvimento" torna-se mais complexo de compreender quando as restrições de aprendizado não são incorporadas às análises da mudança tecnológica. Nesse sentido, o cenário das novas tecnologias, que surgem com baixos impactos ambientais, está muito mais correlacionado com a capacidade de adaptação do que o mero resultado econômico na execução de tais tecnologias (Acemoglu et al. 2009). Além disso, o padrão de riqueza de um país é determinado pela sua capacidade de geração de futuras riquezas cuja tecnologia tem o potencial de proporcionar (Kim 1997).

Portanto, é perfeitamente plausível imaginar que a degradação ambiental tem fortes relações com o domínio da tecnologia e não apenas com o resultado econômico em que a tecnologia nos adéqua. Imaginar a dissociação entre Domínio Tecnológico x Degradação Ambiental, contraria algumas evidências empíricas (Rocha et al. 2009).

Dessa forma, a presente investigação propõe o seguinte modelo empírico ${ }^{13}$

$$
\ln \left(\frac{E_{i t}}{P_{i t}}\right)=\alpha+\gamma_{1} \ln \left(A_{i t}\right)+\gamma_{2}\left(\ln \left(A_{i t}\right)\right)^{2}+\beta^{\prime} X+\mu_{i}+\gamma_{t}+\varepsilon_{i t}
$$

A equação (3) apresenta a relação entre as emissões de $\mathrm{CO}_{2}$ per capita e o nível tecnológico, mensurado pela Produtividade Total dos Fatores (PTF), dado um vetor de variáveis-controle $(\mathrm{X})$. Caso a relação $\mathrm{U}$-invertido seja observada, os parâmetros estimados devem satisfazer às relações estritas $\gamma_{1}>0 ; \gamma_{2}<0$.

A suposição da relação degradação-nível tecnológico é comentada na literatura. ${ }^{14} \mathrm{~A}$ formulação desta ideia parte da prerrogativa de que o aumento da produtividade total dos fatores torna a sustentabilidade técnica mais fácil de ocorrer e, consequentemente, o desenvolvimento sustentável emergiria de maneira mais fácil a partir da utilização de tecnologias mais limpas. Entretanto, melhorias tecnológicas podem implicar numa produção por unidade de recurso ainda maior no futuro, ocasionando uma demanda crescente, ou no mínimo, estável por emissões de poluentes (Stern \& Cleveland 2004, p.12-13).

\footnotetext{
${ }^{11}$ Dosi (1988), Malerba \& Orsenigo (1993), Kim (1997), Aghion \& Howitt (1998), Aghion et al. (2009), Nelson \& Pack (1999), Amsden (2001), Acemoglu et al. (2002), Malerba (2004), Dosi et al. (2010).

${ }^{12}$ Segundo Lee (2000) existem três estágios de desenvolvimento: o estágio da imitação, o estágio da internalização e o estágio da criação.

${ }^{13}$ Acredita-se que a exclusão do termo cúbico no lado direito da equação, comum em vários trabalhos, não desqualifica o modelo proposto. Perman \& Stern (1999) e Stern (2009) consideraram a ausência do termo cúbico por meio de vários procedimentos econométricos - Stern (2009) adota 10 métodos - sem que tal ausência necessariamente consista em um erro de especificação do modelo. A inclusão do termo cúbico tende a controlar os efeitos de heterogeneidade e de autocorrelação serial, caso seja clara a falta de especificação do modelo pela sua ausência. No entanto, no modelo proposto são adotados erros-padrão robustos quanto à heterogeneidade e de autocorrelação (usando os comandos vce(robust) e cluster(id) na programação do STATA).

${ }^{14}$ Ver Stern \& Cleveland (2004) e Stern (2003).
} 
Porém, melhorias no estado tecnológico proporcionam uma produção mais eficiente, isto é, proporcionam a adoção de tecnologias que utilizam menos insumos com altas emissões de poluentes por unidade de produto. Outra consideração baseia-se em mudanças nos processos tecnológicos que permitem emissões cada vez menores de poluentes por unidades de insumo (Stern 2003).

O próprio estado tecnológico contribui para mudanças estruturais que reforçam o progresso técnico. Tais mudanças podem ser acompanhadas por alterações nas instituições estabelecidas que condicionam a trajetória da estrutura produtiva e tecnológica, direcionando-as para emissões cada vez menores de poluentes (Perman \& Stern 1999).

Segundo Panayotou (1993), com os altos níveis de desenvolvimento decorrentes de padrões tecnológicos mais elevados, o próprio percurso estrutural da sociedade conduziria à adoção de tecnologias mais limpas, uma vez que o ambiente institucional que moldaria a aplicação mais eficiente das normas ambientais, juntamente com a conscientização social, resultaria inevitavelmente em nivelamento e declínio gradual da degradação ambiental.

O impacto das melhorias tecnológicas observado nos avanços da produtividade dos países é notoriamente um condicionante da redução da degradação ambiental. Conforme Stern (2003):

"If there were no change in the structure or technology of the economy, pure growth in the scale of the economy would result in a proportional growth in pollution and other environmental impacts." (p. 02)

A próxima seção apresenta a contabilidade do crescimento para calcular a Produtividade Total dos Fatores (PTF) dos países da amostra empregada neste artigo. A calibração para o cálculo da PTF foi feita com base no modelo tradicional de crescimento neoclássico baseado nos trabalhos de Solow (1956, 1957).

\section{Contabilidade do crescimento e alibração para o cálculo da produtividade total dos fatores - PTF}

A partir dos trabalhos de Solow $(1956,1957)$, a contabilidade do crescimento atribui mudanças no produto agregado dos países segundo alterações nos fatores de produção e na produtividade total dos fatores, sendo que esta última constitui o objeto de maior atenção ao modelo.

A versão que inclui o capital humano ao modelo passa a considerar que a mão de obra tende a ser mais produtiva em função da sua qualificação ou do nível de escolaridade. Baseando-se nessa premissa, Hall \& Jones (1996, 1999), e Klenow \& Rodriguez-Clare (1997) demonstraram que o produto agregado entre os países é uma função que combina os estoques de capital físico e os serviços de uma mão de obra qualificada:

$$
Y_{i t}=A_{i t} f\left(K_{i t}, H_{i t}\right)
$$

Na equação (4), " $K$ " corresponde ao estoque de capital físico, " $H$ " ao estoque de capital humano e " $A$ " à produtividade total dos fatores (Hick's Neutra). Bils \& Klenow (2000) afirmam que a escolaridade está positivamente 
relacionada com as taxas de crescimento do produto per capita entre os países. Segundo os autores, países com altos níveis de escolaridade nos anos 1960 exibiam rápidas taxas de crescimento da oferta de mão de obra no mercado de trabalho ao longo do período de 1960-1990.

Segundo Hall \& Jones (1999) o estoque de capital humano diferencia entre os países em detrimento à disparidade existente nos níveis de educação. Assumindo a homogeneidade da mão de obra, o capital humano aumentador da força de trabalho é uma função dos anos de escolaridade " $E$ ":

$$
\begin{gathered}
H_{i t}=h_{i t} L_{i t} \therefore h_{i t}=\exp \left\{\varphi\left(E_{i t}\right)\right\} \\
\varphi: E_{i t} \rightarrow \mathfrak{K e}_{+}^{1}
\end{gathered}
$$

Pela linearidade de $\varphi(\cdot)$, a equação (6) pode ser transformada da seguinte maneira:

$$
\begin{gathered}
H_{i t}=\exp \left\{\frac{d \varphi\left(E_{i t}\right)}{d E_{i t}} E_{i t}\right\} L_{i t} \\
H_{i t}=\exp \left\{\varphi^{\prime}\left(E_{i t}\right) E_{i t}\right\} L_{i t} \\
\varphi^{\prime}\left(E_{i t}\right)>0, E_{i t} \geq 0
\end{gathered}
$$

Assim, países com mão de obra não qualificada possuem um estoque equivalente ao valor de " $L$ ". Alguns pesquisadores ${ }^{15}$ afirmam que a taxa de retorno da escolaridade " $\varphi$ ' $\left(E_{i t}\right)$ " é linear por partes, baseados em estudos das regressões mincerianas ${ }^{16}$ dos salários.

A equação (4) pode ser reestruturada da seguinte forma:

$$
\begin{aligned}
& Y_{i t}=A_{i t} K_{i t}^{\alpha}\left(H_{i t}\right)^{1-\alpha} \\
& \forall \alpha \in(0,1)
\end{aligned}
$$

O produto agregado se diferencia entre os países em decorrência de estoques distintos de capital físico, níveis de escolaridade e produtividade. Rearranjando a equação (10) a produtividade pode ser mensurada da seguinte forma:

$$
A_{i t}=Y_{i t} g\left(K_{i t}, h_{i t}, L_{i t}\right), g(\cdot)=f^{-1}(\cdot)
$$

A produtividade pode ser quantificada desde que, a priori, sejam conhecidos os valores do produto, estoque de capital, níveis de escolaridade e $\varphi(\cdot)$. Seguindo a padronização da contabilidade por alguns autores, ${ }^{17}$ é preferível reformular a equação (11):

$$
A_{i t}=\left\{\frac{Y_{i t}}{L_{i t}}\left(\frac{K_{i t}}{Y_{i t}}\right)^{-\left(\frac{\alpha}{1-\alpha}\right)}\left(h_{i t}\right)^{-1}\right\}^{1-\alpha}
$$

\footnotetext{
${ }^{15}$ Psacharopoulos (1994), Hall \& Jones (1996, 1999), Bils \& Klenow (2000).

${ }^{16}$ Mincer (1974).

${ }^{17}$ Para maiores detalhes veja Hall \& Jones (1996, 1999), Klenow \& Rodriguez-Clare (1997) Benhabib \& Spiegel (2005).
} 
Aplicando logaritmo na equação (12), a produtividade total dos fatores Hick's Neutra pode ser calculada da presente maneira:

$$
\ln A_{i t}=(1-\alpha) \ln \left(\frac{Y_{i t}}{L_{i t}}\right)-(\alpha) \ln \left(\frac{K_{i t}}{Y_{i t}}\right)-(1-\alpha) \varphi^{\prime}\left(E_{i t}\right) \cdot E_{i t}
$$

A produtividade dos países corresponde às diferenças no logaritmo do produto per capita com relação ao logaritmo da participação dos estoques de capital físico e de uma função da escolaridade, para um dado parâmetro " $\alpha$ " conhecido a priori.

Como $\varphi\left(E_{i t}\right)$ corresponde a uma função piercewise, diferentes grupos de valores de " $E$ " proporcionam diferentes taxas de retorno " $\varphi^{\prime}\left(E_{i t}\right)$ ". Hall \& Jones $(1996,1999)$ basearam seus estudos em valores referentes aos de Psacharopoulos (1994). Dessa forma:

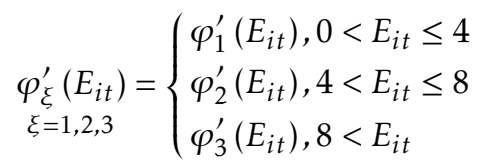

Para os quatro primeiros anos de educação, a taxa de retorno é da ordem de $13,4 \%$, para os quatro anos seguintes, $10,1 \%$, e para acima de oito anos, $6,8 \% .{ }^{18}$ O presente trabalho adotará os valores segundo Psacharopoulos \& Patrinos (2002), considerando para os primeiros quatro anos a taxa de $11,7 \%$ (média da África Subsaariana), até oito anos a taxa de 9,7\% (média mundial) e acima de oito anos a taxa de 7,5\% (média da OECD).

Adicionando as informações da equação (14) na (13) tem-se:

$$
\begin{aligned}
& \ln A_{i t}=(1-\alpha) \ln \left(\frac{Y_{i t}}{L_{i t}}\right)-(\alpha) \ln \left(\frac{K_{i t}}{Y_{i t}}\right)-(1-\alpha) \underset{\substack{\varphi_{\xi}^{\prime} \\
\xi=1,2,3}}{\left(E_{i t}\right) \cdot\left(E_{i t}\right)} \\
& \forall \alpha \in(0,1)
\end{aligned}
$$

Nesta investigação, a produtividade foi calibrada adotando um valor $\alpha=\frac{1}{3}$, de modo similar a Hall \& Jones (1996, 1999).

\section{Fonte dos dados e operacionalização das variáveis}

O modelo de regressão com dados em painel baseou-se numa amostra aleatória de 102 países desenvolvidos, em desenvolvimento e subdesenvolvidos, ver Tabela A.1 no Apêndice, durante o período de 1960-2000. Os dados encontram-se divididos em intervalos de cinco anos $(1960,1965,1970,1975$, 1980, 1990, 1995, 2000).

Optou-se por essa divisão devido, especialmente, ao fato de que na base de dados adotada (Barro \& Lee 2000), a variável escolaridade encontra-se disponibilizada em quinquênios. O emprego de dados anuais exigiria interpolações e traria ao modelo distorções que impactariam significativamente os resultados. Acredita-se que o uso das séries quinquenais não compromete a qualidade dos resultados, ressaltando que as variáveis principais estão expressadas em escalas logarítmicas, de forma que os parâmetros estimados podem

\footnotetext{
${ }^{18}$ Veja Hall \& Jones (1999, p.8) e Psacharopoulos (1994, p.13).
} 
ser interpretados como medidas de elasticidade, o que representa em parte variações percentuais que uma variável exerce sobre a outra (crescimento). Além disso, outros estudos já utilizam esse tipo de procedimento na divisão da amostra, como é o caso de Aghion et al. (2007).

Com o objetivo de calibrar a PTF dos países, adotou-se uma função de produção agregada à inclusão do capital humano a partir das séries de escolaridade média para uma população acima de 25 anos. Esses dados foram extraídos de Barro \& Lee (2000). As séries trabalhadas por esses autores englobam 139 países. Entretanto, o cruzamento entre as variáveis do modelo para evitar um painel não balanceado e com ausência de observações (isto geraria um viés ainda maior nas estimativas de erro-padrão dos estimadores), reduziu o tamanho da amostra para 102 países.

Os dados do PIB per capita foram obtidos no World Development Indicators (WDI), disponibilizados no site do Banco Mundial. Para mensurar a participação do estoque de capital no PIB (K/Y), fez-se uso da razão (Formação Bruta de Capital/PIB) também extraída do site do Banco Mundial.

Para quantificar o impacto da degradação ambiental pelos países utilizouse a emissão de $\mathrm{CO}_{2}$ per capita que também é mencionada na literatura. ${ }^{19}$ As estatísticas de degradação ambiental foram obtidas junto ao Banco Mundial.

As variáveis-controle $(\mathrm{X})$ mencionadas na subseção 2.1 correspondem a: (a) consumo de energia elétrica medido em kWh (Quilowatt-hora) per capita; (b) consumo de energia primária per capita, que corresponde à utilização dos combustíveis brutos antes do seu processamento (a fórmula para seu cálculo encontra-se disponibilizado pela International Energy Agency); ${ }^{20}$ (c) participação do valor adicionado produzido pela indústria em relação ao PIB, que corresponde à intensidade tecnológica da indústria no país; e (d) taxa de crescimento populacional do país.

Os critérios para a seleção das variáveis que compuseram o modelo foram o seu reconhecimento teórico (Tabela 1) e disponibilidade e qualidade de dados. As principais estatísticas descritivas das referidas variáveis são apresentadas no Apêndice, Tabelas A.2 a A.8.

A seguir são apresentadas as estimativas do modelo e a análise teórica que fundamenta o escopo desta investigação.

\section{Análise dos resultados}

A Figura 3 apresenta as emissões de dióxido de carbono ao longo de 1950 a 2000 segundo os grupos de países.

Segundo Thorning \& Illarionov (2005), a América do Norte é responsável por $78,95 \%$ das emissões totais de dióxido de carbono per capita no continente americano. Sendo assim, a região que mais contribui para a emissão de poluentes que intensificam o aquecimento global. Essa considerável participação

\footnotetext{
${ }^{19}$ Outra variável proxy para quantificar a degradação ambiental pelos países constitui-se na emissão de dióxido de enxofre $\left(\mathrm{SO}_{2}\right)$. Veja Stern (2009).

${ }^{20} \mathrm{~A}$ base de cálculo corresponde:

$\underline{\left.\begin{array}{l}\text { Produção interna }+ \text { importações }+\Delta \text { Estoques }-(\text { exportações }+ \\ \text { combustíveis fornecidos a navios e aviões que efectuam transportes internacionais })\end{array}\right]}$

[População]

Veja do site: http: //www. iea.org/stats/index.asp
} 
Tabela 1: Definição das variáveis utilizadas no modelo e a referência com base em estudos correlatos.

\begin{tabular}{|c|c|c|}
\hline $\begin{array}{l}\text { Variável } \\
\mathrm{CO}_{2} \text { per capita }\end{array}$ & $\begin{array}{l}\text { Definição } \\
\mathrm{CO}_{2} \text { per capita }\end{array}$ & $\begin{array}{l}\text { Referências } \\
\text { Emissão de } \mathrm{CO}_{2} \text { per capita }\end{array}$ \\
\hline Produtividade (PTF) & PTF - Hick's Neutra & $\begin{array}{l}\text { Rocha et al. (2009) e Ace- } \\
\text { moglu et al. (2009) }\end{array}$ \\
\hline Energia Elétrica per capita & Consumo & $\begin{array}{l}\text { Stern (2003), Stern \& Cle- } \\
\text { veland (2004), Stern (2009) } \\
\text { e Martin et al. (2011) }\end{array}$ \\
\hline Energia Bruta per capita & $\begin{array}{l}\text { Consumo de Energia } \\
\text { Primária per capita }\end{array}$ & Martin et al. (2011) \\
\hline $\begin{array}{l}\text { Intensidade do Valor Adicio- } \\
\text { nado (Indúst.) }\end{array}$ & VA/PIB & Martin et al. (2011) \\
\hline Crescimento Populacional & $\begin{array}{l}\text { Taxa de Cresc. Populaci- } \\
\text { onal }\end{array}$ & $\begin{array}{l}\text { Stern (2003), Stern \& Cleve- } \\
\text { land (2004), Stern (2009) }\end{array}$ \\
\hline $\ln (h)$ & $\begin{array}{l}\text { ln Capital } \mathrm{Hu}^{-} \\
\text {mano/Trabalhador }\end{array}$ & $\begin{array}{l}\text { Hall \& Jones (1999) e Bils } \\
\text { \& Klenow (2000) }\end{array}$ \\
\hline
\end{tabular}

Fonte: Elaboração própria.

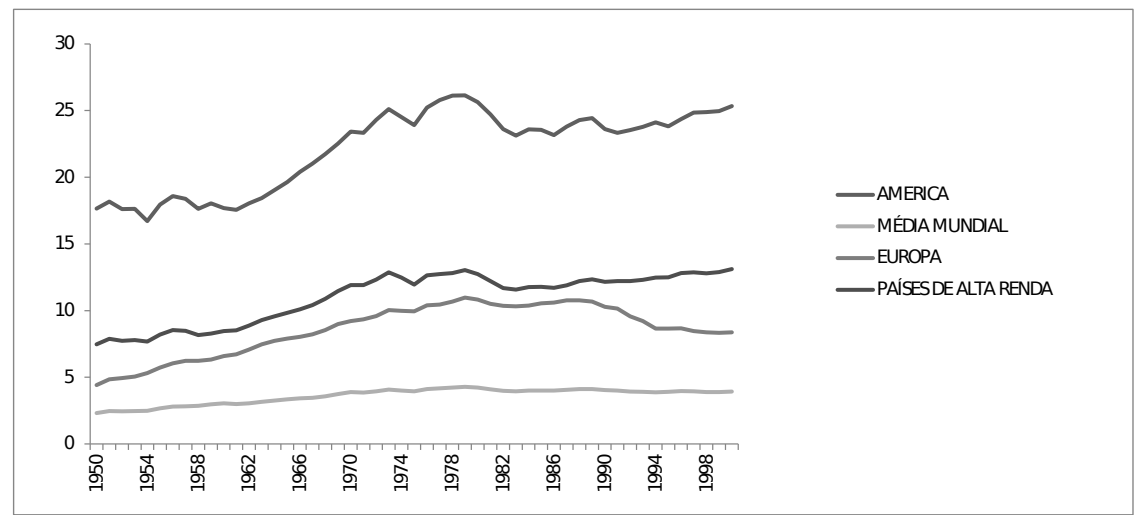

Fonte: Rocha et al. (2009). Disponível também no World Resources Institute. Veja: WWw . wri.org

Figura 3: Evolução das emissões de dióxido de carbono per capita por regiões durante 1950 a 2000.

é uma restrição não apenas climática, mas também da própria capacidade tecnológica dos países restantes. A discrepância das emissões de dióxido de carbono é notória em relação ao continente americano, onde os Estados Unidos respondem pela maior emissão cumulativa ao longo do período.

Uma das principais repercussões das questões climáticas está constituída nos padrões tecnológicos das economias que se encontram nos estágios de avanço em direção à fronteira. As economias mais avançadas "financiaram" seus atuais estágios tecnológicos por meio de emissões de poluentes ao longo do tempo, contribuindo para uma nova e atuante restrição na trajetória das economias mais atrasadas. (Rocha et al. 2009).

A Tabela 2 apresenta as estimativas do modelo proposto segundo o método de estimação. Em todos os métodos os sinais de todos os parâmetros permaneceram iguais, apenas com modificações em suas significâncias.

Analisando o modelo de efeitos fixos, a consistência da estimação é garantida por considerar a correlação entre o vetor de controle fixo e de tempo com 
os regressores. ${ }^{21} \mathrm{O}$ teste Hausman confirma a correlação entre os vetores de controle $\left(\mu_{i} ; \gamma_{t}\right)$ e os regressores, comprovando a consistência do estimador de efeitos fixos.

As variáveis, energia bruta per capita e a intensidade do valor adicionado, apresentam sinal positivo no modelo e com significância em todos os modelos estimados. O aumento do consumo de energia bruta contribui para a degradação ambiental através das emissões de dióxido de carbono per capita. A relação positiva entre valor adicionado e emissões de dióxido baseia-se na relação próxima com o nível tecnológico. Quanto maior a participação do valor adicionado na riqueza, maior o nível tecnológico da economia. Dessa forma, a relação positiva entre intensidade de nível tecnológico e emissão de dióxido de carbono apresenta-se positiva em concordância com o que é enfatizado na literatura. ${ }^{22}$

A relação U-invertido entre as emissões de dióxido de carbono e a Produtividade Total dos Fatores é estatisticamente significativa com relação aos modelos apresentados. Considerando os estágios iniciais do desenvolvimento econômico a adoção de tecnologias "menos limpas" é crucial para o aprendizado tecnológico. À medida que o aprendizado vai se consolidando em um padrão cumulativo, a própria inserção da economia ao cenário da inovação pressiona pela utilização de tecnologias mais limpas, seja pelas mudanças estruturais da sociedade ou pela necessidade de se permanecer em um mercado ainda mais competitivo do ponto de vista de tecnologias ambientalmente sustentáveis.

Segundo Aghion et al. (2009), considerando os recursos naturais como insumos esgotáveis, o estoque de recursos naturais tende a cair consideravelmente caso a economia não adote padrões tecnológicos inovativos. Dessa forma, o crescimento passa a ser sustentável somente se a economia inovar em tecnologias poupadoras desses recursos. O modelo parte da restrição de que as inovações são "verdes", isto é, a adoção de novas tecnologias não gera degradação ambiental.

Partindo de um modelo mais ampliado, considerando a produção de bens tanto por um processo "limpo" quanto "sujo", os autores demonstram que os governos podem "direcionar" o progresso tecnológico por meio da taxação nas inovações inadequadas, isto é, aquelas que reduzem o estoque de recursos naturais, ou no subsídio de pesquisas destinadas à substituição desses recursos.

Acemoglu et al. (2009) apresentaram um modelo teórico considerando uma economia com dois setores, sendo que apenas um adotava tecnologia "suja", o que consequentemente gerava degradação ambiental. Nesse sentido, quando os insumos (sujos e limpos) são suficientemente substituíveis, um crescimento de longo prazo sustentável pode ser alcançado por meio da taxação na produção e na inovação de tecnologias que poupam insumos "sujos". Isso requer um conjunto de políticas articuladas que envolvam a taxação sobre a emissão de carbono na provisão de recursos destinados às pesquisas que gerem inovações de tecnologias mais limpas. Segundo os autores, a demora na implementação dessas políticas pode gerar elevados custos irrecuperáveis (sunk costs) que podem comprometer a fase de transição do crescimento.

As economias com maior gap entre setores intensivos em tecnologias mais "sujas" e "limpas" apresentam uma maior restrição ao crescimento de longo

\footnotetext{
${ }^{21}$ Para maiores detalhes veja Wooldridge (2002).

${ }^{22}$ Para um aprofundamento sobre o tema veja Stern (2009).
} 


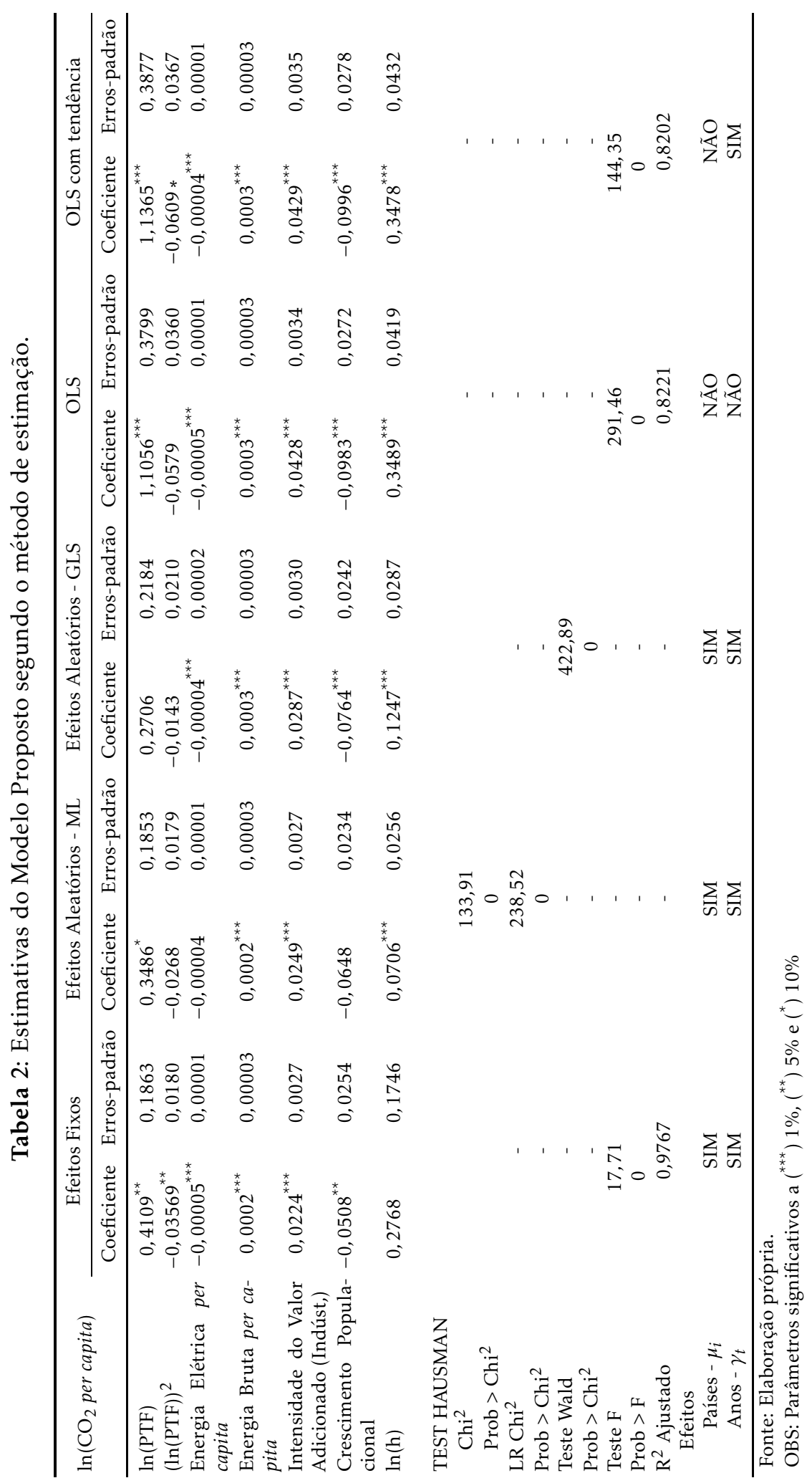


prazo devido a não transição entre as tecnologias de ambos os setores. O maior retardo (em um ponto inicial de um determinado país) possibilita um catch-up mais limitado e com baixo crescimento (sinal negativo da regressão):

"Our analysis also highlights that delaying intervention may be quite costly, not only because it further damages the environment (an effect already recognized in the climate science literature), but also because it widens the gap between dirty and clean technologies, thereby inducing a longer period of catch-up with slower growth." (Acemoglu et al. 2009, p.15)

Perman \& Stern (1999) também apresentam conclusões similares em seus estudos:

"The first countries to develop increasingly specialise towards human and manufactured capital intensive products and 'outsource' production of labour and resource intensive production to developing countries. But because the total number of countries is limited, countries that develop later will find it harder to reduce environmental impacts as there will be less scope to specialise away from resource intensive production" (p. 05).

Adotando valores razoáveis aos parâmetros do modelo, ou seja, os mesmos utilizados nos modelos existentes com tecnologias exógenas e considerando uma substitutibilidade suficiente entre os insumos, é ideal e crucial o redirecionamento das inovações tecnológicas mais "limpas". Sendo assim, uma regulação ambiental "ótima" e adequada, não necessariamente restringe o crescimento de longo prazo (Acemoglu et al. 2009).

Como o padrão tecnológico mais "limpo" vem ganhando espaço por reduzir potenciais desastres climáticos, é bastante perceptiva a predominância dessas tecnologias nas economias situadas ou em avanço em direção à fronteira. Entretanto, uma inovação não surge meramente por acontecimentos tão aleatórios, de fato, ela surge como um fluxo de inovações contínuas e posteriores, que se constituem numa melhoria ou no avanço gradual do original, ou ainda, na criação de novos conhecimentos que serão usados para outras inovações em áreas afins (Breschi et al. 2000). Através dessa perspectiva, os altos níveis de aprendizado e de cumulatividade técnica são oriundos tipicamente de um ambiente econômico caracterizado por contínuas atividades tanto inovadoras, quanto ao acúmulo de um aprendizado necessário para tal finalidade. Isso requer, nos estágios iniciais do aprendizado, uma potencial degradação ambiental pelas economias mais atrasadas.

Com relação ao resultado obtido no indicador de capital humano, esse fato se aproxima das conclusões de recentes pesquisas sobre os reais canais de transmissão do capital humano no desenvolvimento. Conforme os trabalhos de Aghion et al. (2009), Ang et al. (2011) e Rocha (2011), o capital humano é bastante heterogêneo dentro de cada economia, de forma que existe uma composição adequada para cada domínio de tecnologia. Para as economias mais afastadas da fronteira, que adaptam tecnologias já existentes (difusão), um tipo de capital humano menos especializado complementa de forma mais eficiente a tecnologia local. 
Ao contrário desse cenário, nas economias mais avançadas, outro tipo de capital humano mais especializado é rotineiramente demandado nos departamentos de pesquisa. Essa divisão de fatores especializados pode desencadear uma precária associação entre a produtividade e os impactos dessa na degradação ambiental. Isso ocorre devido aos diferentes padrões de tecnologia que são afetados por diferentes fatores, de forma que uma única medida agregada pode não capturar com eficiência a relação Tecnologia x Degradação Ambiental. Nesse sentido, nas economias mais atrasadas, cuja tecnologia se complementa com um tipo específico de capita humano menos especializado, a associação entre o capital humano e a degradação ambiental apresenta-se de forma mais "suave", ao contrário das economias mais avançadas e situadas na fronteira.

\section{Considerações Finais}

A presente investigação analisou os impactos ambientais derivados do nível tecnológico dos países, buscando testar as evidências empíricas da Curva de Kuznets Ambiental - CKA. Nos estágios iniciais do desenvolvimento, a precária regulação ambiental associada aos baixos custos de oportunidade na utilização dos recursos naturais condiciona um padrão de comportamento através de uma relação positiva entre a emissão de poluentes e a riqueza de um país, dada pelo seu PIB per capita. Após certo nível de acumulação, as percepções sociais e a elevação dos custos de oportunidade na utilização dos recursos conduziriam a uma mudança na relação que iria se aproximaria, a priori, de uma curva U-invertido, denominada Curva de Kuznets Ambiental - CKA.

No intuito de testar a hipótese do modelo, foi estimada por meio de uma regressão com dados em painel a consistência do modelo CKA, porém relacionando a emissão de poluentes com a Produtividade Total do Fatores - PTF. Utilizando uma amostra de 102 países durante 1960-2000 e adotando testes estatísticos na validade das estimativas, concluiu-se que o modelo com efeitos fixos é coerente com a literatura. Mesmo com os demais estimadores ainda fica comprovada a relação U-invertido entre a emissão de dióxido de carbono e a PTF, ainda que controlando as variáveis do modelo. O poder de explicação do modelo revelou-se bastante alto ao se comparar com a literatura.

Nesse sentido, numa trajetória inicial do aprendizado, a utilização de tecnologias sujas torna-se imprescindível na provisão de uma base tecnológica necessária para gerar condições suficientes de inovação e, então, a possível transição entre tecnologias sujas e limpas. Vale ressaltar que o alicerce dos atuais padrões tecnológicos de inovação ainda corresponde ao domínio de tecnologias mais sujas e com uma relativa degradação ambiental. Dessa forma, o impacto das regulações ambientais para as economias atrasadas pode comprometer a trajetória de aprendizado, ocasionando o aumento do gap tecnológico entre as economias que buscam avançar e a vizinhança da fronteira (as nações mais desenvolvidas). Neste estudo é importante enfatizar o papel do subsídio nas pesquisas para aliviar o potencial retardo tecnológico das nações atrasadas. O equívoco ao negligenciar tais aspectos pode desencadear um padrão de divergência entre as economias integradas. 


\section{Referências Bibliográficas}

Acemoglu, D., Aghion, P., Bursztyn, L. \& Hemous, D. (2009), The environment and directed technical change, NBER Working Papers 15451, National Bureau of Economic Research, Inc.

Acemoglu, D., Aghion, P., Bursztyn, L. \& Hemous, D. (2012), 'The environment and directed technical change', American Economic Review 102(1), 131166.

Acemoglu, D., Aghion, P. \& Zilibotti, F. (2002), Distance to frontier, selection, and economic growth, NBER Working Paper W9066.

Aghion, P., Alesina, A. \& Trebbi, F. (2007), Democracy, technology, and growth, NBER Working Paper W13180.

Aghion, P., Boustan, L., Hoxby, C. \& Vandenbussche, J. (2009), The causal impact of education on economic growth: Evidence from united states, Conference, Brookings Papers on Economic Activity.

Aghion, P. \& Howitt, P. (1998), Endogenous Growth Theory, MIT Press.

Amsden, A. (2001), The rise of The Rest: challenges to the west from lateindustrializing economies, New York: Oxford University Press.

Andreoni, J. \& Levinson, A. (2001), 'The simple analytics of the environmental kuznets curve.', Journal of Public Economics 80, 269-286.

Ang, J. B., Madsen, J. B. \& Islam, M. R. (2011), 'The effects of human capital composition on technological convergence', Journal of Macroeconomics $33,465-476$.

Arrow, K., Bolin, B., Costanza, R., Dasgupta, P., Folke, C., Holling, C. S., Jansson, B. O., Levin, S., Maler, K. G., Perrings, C. \& Pimentel, D. (1995), 'Economic growth, carrying capacity, and the environment', Science 268, 520521.

Baltagi, B. H. (2008), Econometric Analysis of Panel Data, 4th edition edn, Chichester.

Barro, R. J. \& Lee, J. (2000), International data on educational attainment: Updates and implications, Working Paper 42, CID.

Benhabib, J. \& Spiegel, M. M. (2005), Human Capital and Technology Difusión, Handbook of Economic Growth. Amsterdam: Elsevier North-Holland.

Bils, M. \& Klenow, P. (2000), 'Does schooling cause growth or the other way around?', University of Chicago.

Breschi, S., Malerba, F. \& Orsenigo, L. (2000), 'Technological regimes and schumpeterian patterns of innovation', Economic Journal 110, 388-410.

Bruvoll, A. \& Medin, H. (2003), 'Factors behind the environmental kuznets curve: A decomposition of the changes in air pollution', Environmental and Resource Economics 24, 27-48. 
Bulte, E. H. \& Van Soest, D. P. (2001), 'Environmental degradation in developing countries: households and the (reverse) environmental kuznets curve', Journal of Development Economics 65, 225-235.

Caselli, F. \& Coleman, W. J. (2006), 'The world technology frontier', American Economic Review 96, 499-522.

Cole, M. A. (2004), 'Trade, the pollution haven hypothesis and the environmental kuznets curve: examining the linkages', Ecological Economics 48, 7181 .

Costantini, V. \& Martini, C. (2007), A modified environmental kuznets curve for sustainable development assessment using panel data, Working Papers 107, Fondazione Eni Enrico Mattei.

Dasgupta, S., Laplante, B., Wang, H. \& Wheeler, D. (2002), 'Confronting the environment kuznets curve', Journal of Economic Perspective 16, 147-168.

De Bruyn, S. M., Van Den Bergh, J. C. J. M. \& Opschoor, J. B. (1998), 'Economic growth and emissions: reconsidering the empirical basis of environmental kuznets curves', Ecological Economics 25, 161-175.

Deacon, R. T. \& Norman, C. S. (2006), 'Does the environmental kuznets curve describe how individual countries behave?', Land Economics 82, 291-315.

Dosi, G. (1988), 'Sources, procedures and microeconomic effects of innovation', Journal of Economic Literature 26(3), 1120-1171.

Dosi, G., Fagiolo, G. \& Roventini, A. (2010), 'Schumpeter meeting keynes: A policy-friendly model of endogenous growth and business cycles', Journal of Economic Dynamics E Control 34(9), 1748-1767.

Earth Trends (2001), 'The enviromental information portal, climate and atmosphere, 1999-2000', World Resources Institute.

URL: Disponivel em <http://earthtrends.wri.org> Acessado em 10/07/2011

Ekins, P. (1997), 'The kuznets curve for the environment and economic growth: examining the evidence', Environment and Planning A 29, 805-830.

Grossman, G. M. \& Krueger, A. B. (1991), Economic growth and the environmental, NBER Working Paper 3914.

Grossman, G. M. \& Krueger, A. B. (1995), Environmental impacts of a north american free trade agreement, NBER Working Paper 3914.

Hall, R. E. \& Jones, C. I. (1996), The productivity of nations, NBER Working Paper W5812, National Bureau of Economic Research.

Hall, R. E. \& Jones, C. I. (1999), 'Why do some countries produce so much more output per worker than others?', Quarterly Journal of Economics 114(1), 83-116.

Harbaugh, W., Levinson, A. \& Wilson, D. M. (2002), 'Reexamining the empirical evidence for an environmental kuznets curve', Review of Economics and Statistics 84, 541-551. 
Hausman, J. A. (1978), 'Specification tests in econometrics', Econometrica 46, 1251-1271.

He, J. (2007), 'Is the environmental kuznets curve hypothesis valid for developing countries?', A survey. Cahiers de recherche 07-03, Departement d'Economique de la Faculte d'administration à l'Universite de Sherbrooke.

Hsiao, C. (2003), Analysis of Panel Data, 2nd edition edn, Cambridge University Press.

Kim, L. (1997), Imitation to Innovation. The dynamics of Korea's technological learning, Boston: Harvard Business Scholl Press.

Klenow, P. J. \& Rodriguez-Clare, A. (1997), 'The neoclassical revival in growth economics: has it gone too far?', NBER macroeconomics Annual 12, 73103.

Lee, W. Y. (2000), The Role of Science and Technology Policy in Korea's Industrial Development, Cambridge: Cambridge University Press, chapter Technology Learning and Innovation: Experiences of Newly Industrializing Economies.

Lucas, R. E. B., Wheeler, D. \& Hettige, H. (1992), Economic development, environmental regulation and the international migration of toxic industrial pollution: 1960-1988, World Bank Discussion Paper 159, International Trade and the Environment. Washington DC.

Malerba, F. (2004), Sectoral Systems of Innovation - Concepts, Issues and Analyses of Six Major Sectors in Europe, Cambridge University Press.

Malerba, F. \& Orsenigo, L. (1993), 'Technological regimes and firm behavior. industrial \& corporate change', Oxford 2(1), 45-72.

Malerba, F. \& Orsenigo, L. (1997), 'Technological regimes and sectoral patterns of innovative activities', Industrial and Corporate Change 6, 83-117.

Martin, R., De Preux, L. B. \& Wagnerin, U. J. (2011), The impacts of the climated change levy on manufacturing, Nber working paper.

Mincer, J. (1974), Schooling, Experience, and Earnings, New York: Columbia University Press.

Nelson, R. R. \& Pack, H. (1999), 'The asian miracle and modern growth theory', The Economic Journal 109, 416-436.

Panayotou, T. (1993), Empirical tests and policy analysis of environmental degradation at different stages of economic development, Working Paper WP238, Technology and Employment Programme, International Labour Office, Geneva.

Pearson, P. J. G. (1994), 'Energy, externalities, and environmental quality: will development cure the ills it creates', Energy Studies Review 6, 199-216.

Perman, R. \& Stern, D. I. (1999), The environmental kuznets curve: Implications of non-stationarity, Working Papers in Ecological Economics 9901, Australian National University, Centre for Resource and Environmental Studies, Ecological Economics Program. 
Perman, R. \& Stern., D. I. (2001), Sustainable development, growth theory, environmental Kuznets curves and discounting, Environmental Economics, in Encyclopedia of Life Support Systems, UNESCO.

Psacharopoulos, G. (1994), 'Returns to investment in education: A global update', World Development 22, 1325-1343.

Psacharopoulos, G. \& Patrinos, H. (2002), Returns to investment in Education; a futher update.

Rocha, L. A. (2011), Crescimento, Fronteira Tecnológica e a Hipótese da Relatividade do Capital Humano, Tese de doutoramento, Unicamp, 145p.

Rocha, L. A., Silveira, J. M. F. J., Andrade, D. C., Lima, D. A. L. L. \& Pereira, A. M. (2009), Efeitos do aquecimento global no hiato tecnológico dos países, in 'VIII Encontro da Sociedade Brasileira de Economia Ecologia, Cuiabá MT'.

Selden, T. M. \& Song, D. (1994), 'Environmental quality and development: Is there a kuznets curve for air pollution?', Journal of Environmental Economics and Environmental Management 27, 147-162.

Shafik, N. \& Bandyopadhyay, S. (1992), Economic growth and environmental quality: Time series and cross-country evidence, Background paper for the world development report, The World Bank, Washington DC.

Solow, R. (1956), 'A contribution to the theory of economic growth', Quarterly Journal of Economics 70, 65-94.

Solow, R. (1957), 'Technical change and the aggregate production function', Review of Economics and Statistics 70, 65-94.

Stern, D. (2003), 'The rise and fall of the environmental kuznets curve', World Development 32, 1419-1439.

Stern, D. I. (2009), Between estimates of the environmental kuznets curve, Environmental Economics Research Hub Research Reports 0934, Environmental Economics Research Hub, Crawford School, Australian National University.

Stern, D. I., Auld, T., Common, M. S. \& Sanyal, K. K. (1998), Is there an environmental kuznets curve for sulfur?, Working Papers in Ecological Economics 9804, Australian National University, Centre for Resource and Environmental Studies, Ecological Economics Program.

Stern, D. I. \& Cleveland, C. J. (2004), Energy and economic growth, Rensselaer Working Papers in Economics 0410, Rensselaer Polytechnic Institute, Department of Economics.

Stern, D. I. \& Common, M. S. (2001), 'Is there an environmental kuznets curve for sulfur?', Journal of Environmental Economics and Environmental Management 41, 162-178.

Stern, D. I., Common, M. S. \& Barbier, E. B. (1996), 'Economic growth and environmental degradation: the environmental kuznets curve and sustainable development', World Development 24, 1151-1160. 
Suri, V. \& Chapman, D. (1998), 'Economic growth, trade and the energy: implications for the environmental kuznets curve', Ecological Economics 25, 195-208.

Thorning, M. \& Illarionov, A. (2005), 'Climate chance policy and economic growth; a way forward to ensurece botht', Brussels - Belgium: International Council for Capital Formation. Institute of Economic Analysis, Instituto Bruno Leone.

Torras, M. \& Boyce, J. K. (1998), 'Income, inequality and pollution: a reassessment of the environmental kuznets curve', Ecological Economics 25, 147-170.

Vollebergh, H. R. J., Melenberg, B. \& Dijkgraaf, E. (2009), 'Identifying reduced-form relations with panel data: The case of pollution and income', Journal of Environmental Economics and Management 58, 27-42.

Wagner, M. (2008), 'The carbon kuznets curve: A cloudy picture emitted by bad econometrics', Resource and Energy Economics 30, 388-408.

Wooldridge, J. (2002), Econometric Analysis of Cross-section and Panel Data, MIT Press. 


\section{Apêndice $A$}

A Tabela A.1 apresenta o grupo de países considerados no modelo empírico.

Tabela A.1: Países Adotados no Modelo de Regressão.

\begin{tabular}{|c|c|c|c|}
\hline Algeria & Fiji & Kuwait & Senegal \\
\hline Argentina & Finland & Lesotho & Sierra Leone \\
\hline Australia & France & Liberia & Singapore \\
\hline Austria & Gambia, The & Malawi & South Africa \\
\hline Bahrain & Germany & Malaysia & Spain \\
\hline Bangladesh & Ghana & Mali & Sri Lanka \\
\hline Barbados & Greece & Malta & Sudan \\
\hline Belgium & Guatemala & Mauritania & Swaziland \\
\hline Benin & Guyana & Mauritius & Sweden \\
\hline Bolivia & Haiti & Mexico & Switzerland \\
\hline Botswana & Honduras & Mozambique & $\begin{array}{l}\text { Syrian Arab Re- } \\
\text { public }\end{array}$ \\
\hline Brazil & Hong Kong, China & Nepal & Thailand \\
\hline Burundi & Hungary & Netherlands & Togo \\
\hline Cameroon & Iceland & New Zealand & $\begin{array}{l}\text { Trinidad and To- } \\
\text { bago }\end{array}$ \\
\hline Canada & India & Nicaragua & Tunisia \\
\hline $\begin{array}{l}\text { Central African } \\
\text { Republic }\end{array}$ & Indonesia & Niger & Turkey \\
\hline Chile & Iran, Islamic Rep. & Norway & Uganda \\
\hline China & Iraq & Pakistan & $\begin{array}{ll}\text { United } & \text { Arab } \\
\text { Emirates } & \end{array}$ \\
\hline Colombia & Ireland & Panama & $\begin{array}{l}\text { United King- } \\
\text { dom }\end{array}$ \\
\hline Costa Rica & Israel & Papua New Guinea & United States \\
\hline Cyprus & Italy & Paraguay & Uruguay \\
\hline Denmark & Jamaica & Peru & Venezuela, RB \\
\hline $\begin{array}{l}\text { Dominican Repu- } \\
\text { blic }\end{array}$ & Japan & Philippines & Zambia \\
\hline Ecuador & Jordan & Poland & Zimbabwe \\
\hline Egypt, Arab Rep. & Kenya & Portugal & \\
\hline El Salvador & Korea, Rep. & Rwanda & \\
\hline
\end{tabular}

Fonte: Elaboração própria.

As Tabelas A.2 a A.8 apresentam as principais estatísticas descritivas das variáveis empregadas no modelo estimado. 
Tabela A.2: Estatísticas descritivas da Variável $\mathrm{CO}_{2}$ per capita.

\begin{tabular}{ccccc}
\hline Ano & Média & Desvio Padrão & Mínimo & Máximo \\
\hline 1960 & 2,366 & 4,051 & 0 & 28,05 \\
1965 & 3,249 & 8,077 & 0 & 75,14 \\
1970 & 4,127 & 8,222 & 0,01 & 67,82 \\
1975 & 4,139 & 7,127 & 0,01 & 58,57 \\
1980 & 4,391 & 6,005 & 0,03 & 36,32 \\
1985 & 4,229 & 5,858 & 0,03 & 35,37 \\
1990 & 4,357 & 5,543 & 0,03 & 29,29 \\
1995 & 4,654 & 5,988 & 0,04 & 30,24 \\
2000 & 5,034 & 7,005 & 0,04 & 41,77 \\
\hline
\end{tabular}

Fonte: Elaboração própria.

Tabela A.3: Estatísticas descritivas da Variável Produtividade.

\begin{tabular}{ccccc}
\hline Ano & Média & Desvio Padrão & Mínimo & Máximo \\
\hline 1960 & 182,203 & 143,815 & 31,053 & 688,05 \\
1965 & 241,021 & 277,961 & 37,902 & 2017,421 \\
1970 & 254,206 & 254,087 & 33,524 & 1821,352 \\
1975 & 284,558 & 277,31 & 30,514 & 1450,492 \\
1980 & 271,982 & 248,892 & 33,419 & 1074,857 \\
1985 & 287,763 & 268,348 & 32,424 & 949,93 \\
1990 & 286,675 & 270,959 & 26,621 & 986,021 \\
1995 & 300,897 & 307,354 & 38,851 & 1085,081 \\
2000 & 326,521 & 338,009 & 14,401 & 1123,533 \\
\hline
\end{tabular}

Fonte: Elaboração própria.

Tabela A.4: Estatísticas descritivas da Variável Energia Elétrica per capita.

\begin{tabular}{cccrc}
\hline Ano & Média & Desvio Padrão & Mínimo & Máximo \\
\hline 1960 & 2055,531 & 1793,919 & 89,82 & 7681,66 \\
1965 & 2765,075 & 2431,346 & 139,23 & 11416,87 \\
1970 & 3864,231 & 2945,01 & 214,21 & 13449,83 \\
1975 & 1916,136 & 2819,269 & 6,57 & 16315,2 \\
1980 & 2449,727 & 3411,886 & 12,27 & 18701,05 \\
1985 & 2886,227 & 4091,432 & 22 & 22556,47 \\
1990 & 3252,42 & 4401,799 & 34,79 & 23353,77 \\
1995 & 3618,992 & 4660,853 & 29,86 & 24523,85 \\
2000 & 4181,492 & 5306,312 & 35,34 & 26220,64 \\
\hline
\end{tabular}

Fonte: Elaboração própria. 
Tabela A.5: Estatísticas descritivas da Variável Energia Bruta per capita.

\begin{tabular}{ccccc}
\hline Ano & Média & Desvio Padrão & Mínimo & Máximo \\
\hline 1960 & 1965,127 & 1271,511 & 302,99 & 5652,22 \\
1965 & 2397,094 & 1401,753 & 431,79 & 6323,81 \\
1970 & 3172,423 & 1689,942 & 503,38 & 7593,37 \\
1975 & 1728,799 & 1861,491 & 85,47 & 8884,38 \\
1980 & 2037,96 & 2291,664 & 93,52 & 11046,55 \\
1985 & 2091,631 & 2351,696 & 97,33 & 11044,85 \\
1990 & 2208,425 & 2378,032 & 110,93 & 12415,62 \\
1995 & 2401,524 & 2528,57 & 124,9 & 12610,56 \\
2000 & 2576,615 & 2682,092 & 132,92 & 11501,78 \\
\hline
\end{tabular}

Fonte: Elaboração própria.

Tabela A.6: Estatísticas descritivas da Variável Intensidade Valor Adicionado (Indúst.).

\begin{tabular}{clcrc}
\hline Ano & Média & Desvio Padrão & Mínimo & Máximo \\
\hline 1960 & 22,61 & 11,753 & 3,89 & 58,98 \\
1965 & 25,745 & 13,342 & 3,47 & 70,49 \\
1970 & 29,597 & 12,06 & 6,94 & 67,2 \\
1975 & 31,598 & 12,969 & 8,16 & 79,09 \\
1980 & 32,039 & 12,409 & 4,49 & 77,23 \\
1985 & 30,815 & 10,983 & 9,88 & 64,04 \\
1990 & 30,954 & 10,602 & 11,06 & 63,69 \\
1995 & 29,594 & 9,328 & 5,27 & 54,55 \\
2000 & 30,166 & 11,651 & 11,62 & 84,38 \\
\hline
\end{tabular}

Fonte: Elaboração própria.

Tabela A.7: Estatísticas descritivas da Variável Crescimento Populacional.

\begin{tabular}{ccccc}
\hline Ano & Média & Desvio Padrão & Mínimo & Máximo \\
\hline 1960 & 2,315 & 1,281 & $-0,33$ & 8,96 \\
1965 & 2,308 & 1,473 & 0,07 & 11,58 \\
1970 & 2,226 & 1,699 & $-0,58$ & 14,33 \\
1975 & 2,242 & 1,828 & $-0,59$ & 16,4 \\
1980 & 2,126 & 1,398 & $-0,51$ & 9,73 \\
1985 & 1,909 & 1,319 & $-1,92$ & 5,78 \\
1990 & 1,785 & 1,228 & $-1,99$ & 5,37 \\
1995 & 1,648 & 1,12 & $-1,92$ & 5,59 \\
2000 & 1,627 & 1,261 & $-0,53$ & 6,69 \\
\hline
\end{tabular}

Fonte: Elaboração própria. 
Tabela A.8: Estatísticas descritivas da Variável Capital Humano (h).

\begin{tabular}{ccccc}
\hline Ano & Média & Desvio Padrão & Mínimo & Máximo \\
\hline 1960 & 1,468 & 0,316 & 1,01 & 2,169 \\
1965 & 1,479 & 0,317 & 1,014 & 2,169 \\
1970 & 1,513 & 0,329 & 1,006 & 2,221 \\
1975 & 1,545 & 0,327 & 1,018 & 2,224 \\
1980 & 1,589 & 0,306 & 1,05 & 2,247 \\
1985 & 1,631 & 0,299 & 1,058 & 2,233 \\
1990 & 1,666 & 0,286 & 1,076 & 2,261 \\
1995 & 1,72 & 0,286 & 1,096 & 2,289 \\
2000 & 1,755 & 0,29 & 1,107 & 2,3 \\
\hline
\end{tabular}

Fonte: Elaboração própria. 